\title{
SELETIVIDADE DE HERBICIDAS INIBIDORES DE ALS EM DIFERENTES ESTÁDIOS DE DESENVOLVIMENTO DO ARROZ DE TERRAS ALTAS ${ }^{1}$
}

\author{
Fabiano André Petter ${ }^{2}$, Alan Mário Zuffo ${ }^{2}$, Leandro Pereira Pacheco²
}

\section{ABSTRACT \\ SELECTIVITY OF ALS INHIBITORS HERBICIDES AT DIFFERENT STAGES OF UPLAND RICE DEVELOPMENT}

The availability of herbicides registered for upland rice is still limited, increasing the management difficulty level for weeds under this crop system. The objective of this study was to evaluate the effect of the ALS inhibitors herbicides application, at different periods, on upland rice (cv. Cambará). The experimental design was randomized blocks with four replications, in a $5 \times 3$ factorial scheme, consisting of the herbicide treatments penoxsulam (36 $\left.\mathrm{g} \mathrm{ha}^{-1}\right)$, bispiribaque-sodium (50 $\left.\mathrm{g} \mathrm{ha}^{-1}\right)$, pirazossulfuromethyl (20 $\left.\mathrm{g} \mathrm{ha}^{-1}\right), 2,4-\mathrm{D}\left(670 \mathrm{~g} \mathrm{ha}^{-1}\right)$, and a control, and three application periods: 15,30 , and 45 days after emergence (DAE). Plant phytotoxicity, height, and dry biomass were evaluated at 7,14 , and 28 days after application (DAA), and also the number of panicles $\mathrm{m}^{-2}$, number of grains panicle ${ }^{-1}$, and yield. It was observed plant phytotoxicity and height decreasing only when applying bispiribaque-sodium, at 15 and 30 DAE. The plant dry biomass was not affected by herbicide application. The number of grains panicle ${ }^{-1}$ decreased only for pirazossulfurom-ethyl, at 45 DAE. Yield decreased with the pirazossulfurom-ethyl and penoxsulam application, at 45 DAE. Generally the best herbicide application period was $30 \mathrm{DAE}$.

KEY-WORDS: Oryza sativa L.; phytotoxicity; biomass.

\section{INTRODUÇÃO}

A produção brasileira de arroz encontra-se dispersa em todo o território nacional, com dois tipos principais de sistemas básicos de produção: o arroz de terras altas e o irrigado. Na região Centro-Oeste, há predominância do arroz de terras altas, conhecido por apresentar produções menos expressivas. Todavia, seu uso tem sido crescente no sistema de rotação com a cultura da soja, em razão do menor custo de produção e preços atraentes do produto no mercado (Ferreira \& Villar 2003).

\section{RESUMO}

A disponibilidade de herbicidas registrados para o arroz de terras altas ainda é limitada, elevando o grau de dificuldade do manejo de plantas daninhas, neste sistema de cultivo. Objetivouse, com este trabalho, verificar o efeito da aplicação de herbicidas inibidores de ALS, em diferentes épocas, na cultura do arroz de terras altas (cv. Cambará). O delineamento experimental foi o de blocos ao acaso, com quatro repetições, em esquema fatorial $5 \times 3$, constituído pelos tratamentos herbicidas penoxsulam (36 $\left.\mathrm{g} \mathrm{ha}^{-1}\right)$, bispiribaque-sódico (50 $\left.\mathrm{g} \mathrm{ha}^{-1}\right)$, pirazossulfurometílico $\left(20 \mathrm{~g} \mathrm{ha}^{-1}\right), 2,4-\mathrm{D}\left(670 \mathrm{~g} \mathrm{ha}^{-1}\right)$ e uma testemunha, e três épocas de aplicação: 15, 30 e 45 dias após a emergência (DAE). Foram avaliadas a fitointoxicação, altura e fitomassa seca das plantas, aos 7, 14 e 28 dias após a aplicação (DAA), número de panículas $\mathrm{m}^{-2}$, número de grãos panícula ${ }^{-1} \mathrm{e}$ produtividade. Observou-se fitotoxicidade à cultura e redução na altura das plantas apenas com a aplicação de bispiribaque-sódico, aos 15 e 30 DAE. A fitomassa seca das plantas não foi influenciada pela aplicação dos herbicidas. Houve redução no número de grãos panícula $^{-1}$ apenas para pirazossulfurom-etílico, aos 45 DAE. A produtividade foi reduzida com a aplicação de penoxsulam e pirazossulfurom-etílico, aos 45 DAE. De maneira geral, a melhor época de aplicação dos herbicidas foi $30 \mathrm{DAE}$.

PALAVRAS-CHAVE: Oryza sativa L.; fitointoxicação; fitomassa.

A cultura do arroz de terras altas, pouco exigente em insumos e com boa tolerância a solos ácidos, teve destacado papel como cultura de abertura de novas áreas, durante o processo de ocupação agrícola da região dos Cerrados, iniciado na década de 1960 (Pinheiro 2006). Em Mato Grosso, terceiro produtor de arroz no ranking nacional, os orizicultores estão voltando a áreas antigas e, aos poucos, gerando o novo status do arroz como cultura principal (Beling 2007), apesar de sua forte sensibilidade a fatores climáticos.

O desenvolvimento de cultivares de arroz com maior potencial produtivo, aliado à alta fertilidade, 
em solos cultivados anteriormente com soja, tem proporcionado elevadas produtividades e rentabilidade ao produtor rural. Todavia, a inserção da cultura em área de semeadura direta de soja tem apresentado alguns problemas, tais como a dificuldade de se adequar a este sistema de semeadura e o controle de plantas daninhas, uma vez que a maioria das áreas com soja é altamente infestada por muitas espécies (Pacheco et al. 2009). Altas infestações de plantas daninhas, quando não controladas adequadamente, podem ocasionar perdas de até $50 \%$ na produtividade da cultura do arroz (Kluthcouski et al. 1995).

O controle químico de plantas daninhas, no sistema de cultivo de arroz em "terras velhas", apresenta elevado grau de dificuldade, principalmente para os herbicidas graminicidas, pois apresentam condições específicas de uso, que, quando não observadas, podem afetar o desenvolvimento da cultura. De acordo com Cobucci \& Portela (2001), a carência de produtos e tecnologia para o controle de plantas daninhas, em arroz de terras altas, somada à baixa capacidade de competição do arroz, constituem os principais obstáculos para introdução da cultura em sistemas agrícolas de manejo intensivo. Segundo os autores, devido ao crescimento inicial lento e ao baixo porte das cultivares modernas, a cobertura eficiente do solo só ocorre entre 40 e 50 dias após a semeadura. Rahmam (1992) relatou que a cultura do arroz deve permanecer livre de plantas daninhas entre 15 e 45 dias, após a sua emergência.

Diversas são as estratégias de manejo que visam a aumentar o espectro de ação e melhorar o controle da infestação, por maior período de tempo. Todavia, a disponibilidade de herbicidas recomendados atualmente, para o arroz de terras altas, ainda é limitada. Dessa forma, a aplicação sequencial em pré-plantio e pós-emergência, ou a associação de dois pós-emergentes com diferentes espectros de ação, pode resultar em controle mais eficiente (Cobucci \& Noldin 1999). Entretanto, também pode acarretar uma série de problemas à cultura, principalmente em relação à fitointoxicação.

Dentre os herbicidas utilizados no manejo integrado, na cultura do arroz, destacam-se os inibidores da enzima ALS (acetolactato sintetase), chave para os processos de biossíntese de aminoácidos de cadeia ramificada (valina, leucina e isoleucina). Os herbicidas com este mecanismo de ação são altamente utilizados em sistemas de cultivo do arroz irrigado e pouco utilizados em arroz de terras altas.
Leite et al. (1998) e Vidal (2002) constataram que estes produtos apresentam amplo espectro de ação e baixa toxicidade ao homem e animais, além de alta capacidade de translocação.

Dessa forma, herbicidas inibidores de ALS podem ser uma importante ferramenta no controle de plantas daninhas, na cultura do arroz de terras altas. Todavia, ainda são escassas as informações sobre o uso destas moléculas, neste sistema de cultivo.

Objetivou-se, com este trabalho, avaliar a seletividade de herbicidas inibidores de ALS recomendados para a cultura do arroz irrigado, em diferentes estádios de desenvolvimento do arroz de terras altas.

\section{MATERIAL E MÉTODOS}

O experimento foi conduzido a campo, no município de Nova Xavantina, MT (14\%41'46"S, $52^{\circ} 20^{\prime} 53^{\prime}$ 'W e altitude de $310 \mathrm{~m}$ ), entre novembro de 2009 a abril de 2010, em solo classificado como Latossolo Vermelho distrófico - LVd (Embrapa 1999). A análise textural do solo, na camada de 0-0,20 m, apresentou $400 \mathrm{~g} \mathrm{~kg}^{-1}$ de argila, $100 \mathrm{~g} \mathrm{~kg}^{-1}$ de silte e $500 \mathrm{~g} \mathrm{~kg}^{-1}$ de areia. A composição química do solo da área experimental está apresentada na Tabela 1.

O clima da região é do tipo Aw, segundo a classificação de Köppen, com duas estações bem definidas, sendo uma seca, que vai de maio a setembro, e outra chuvosa, de outubro a abril. As condições climáticas ocorridas durante a condução do experimento são apresentadas na Figura 1.

$\mathrm{O}$ arroz foi cultivado em sistema de plantio convencional, em área anteriormente cultivada com soja, onde, dois dias antes da semeadura, foi realizada uma operação de preparo de solo com grade niveladora. A semeadura do arroz, cultivar Cambará, foi realizada no dia 20 de dezembro de 2009, em espa-

Tabela 1. Composição química do solo $(0-0,20 \mathrm{~m})$ da área experimental, antes da instalação do experimento (Nova Xavantina, MT, safra 2007/2008).

\begin{tabular}{|c|c|c|c|c|c|c|c|}
\hline \multirow{2}{*}{$\begin{array}{c}\mathrm{pH} \\
\mathrm{CaCl}_{2}\end{array}$} & $\mathrm{P}$ (Melich) & $\mathrm{K}$ & $\mathrm{Ca}$ & $\mathrm{Mg}$ & $\mathrm{Al}$ & $\mathrm{H}+\mathrm{Al}$ & \multirow{2}{*}{$\begin{array}{l}\text { M.O. }^{1} \\
\mathrm{~g} \mathrm{dm}^{-3}\end{array}$} \\
\hline & \multicolumn{2}{|c|}{$\mathrm{mg} \mathrm{dm}^{-3}$} & \multicolumn{4}{|c|}{$\mathrm{cmol}_{\mathrm{c}} \mathrm{dm}^{-3}$} & \\
\hline 5,2 & 11,6 & 70,0 & 2,7 & 0,8 & 0,1 & 5,2 & 29,0 \\
\hline $\mathrm{V}^{2}$ & $\mathrm{CTC}^{3}$ & $\mathrm{Fe}$ & B & $\mathrm{Mn}$ & $\mathrm{Zn}$ & $\mathrm{Cu}$ & $\mathrm{S}$ \\
\hline$\%$ & $\mathrm{cmol}_{\mathrm{c}} \mathrm{dm}^{-3}$ & 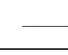 & 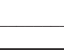 & $\mathrm{m}$ & $\mathrm{dm}^{-3}$ & & \\
\hline 41 & 8,8 & 44 & 0,2 & 24 & 1,5 & 2,4 & 6,4 \\
\hline
\end{tabular}




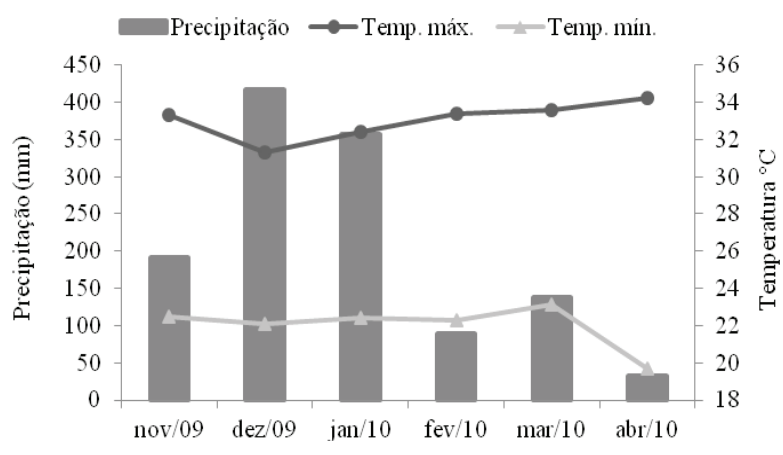

Figura 1. Precipitação $(\mathrm{mm})$ e temperatura média máxima e mínima $\left({ }^{\circ} \mathrm{C}\right)$ mensal ocorridas durante a condução do experimento. Fonte: Estação Experimental do Inmet, em Nova Xavantina, MT.

çamento entrelinhas de $0,20 \mathrm{~m}$, com 80 sementes por metro de sulco. A adubação de base foi constituída por $150 \mathrm{~kg} \mathrm{ha}^{-1} \mathrm{da}$ fórmula $05-25-15$, uniformemente distribuída ao longo dos sulcos de semeadura. A adubação de cobertura foi realizada com $160 \mathrm{~kg} \mathrm{ha}^{-1}$ da fórmula 20-00-00, dividida aos 25 e 32 dias após a emergência (DAE).

O delineamento experimental foi o de blocos ao acaso, com quatro repetições, em esquema fatorial $5 \times 3$, composto pelos tratamentos herbicidas penoxsulam (36 $\left.\mathrm{g} \mathrm{ha}^{-1}\right)$, bispiribaque-sódico $\left(50 \mathrm{~g} \mathrm{ha}^{-1}\right)$, pirazossulfurom-etílico $\left(20 \mathrm{~g} \mathrm{ha}^{-1}\right), 2,4-\mathrm{D}$ $\left(670 \mathrm{~g} \mathrm{ha}^{-1}\right)$ e uma testemunha capinada e três épocas de aplicação: 15, 30 e 45 dias após a emergência (DAE). Por ser comumente utilizado no cultivo do arroz de terras altas, o herbicida 2,4-D foi incluído entre os tratamentos, como parâmetro de referência. As parcelas foram compostas por uma área de $4 \mathrm{~m}$ x $4 \mathrm{~m}$, utilizando-se vinte linhas da cultura, com área útil perfazendo $9 \mathrm{~m}^{2}$, considerando-se o descarte de $1 \mathrm{~m}$, em todas as extremidades.

Os tratamentos foram realizados utilizando-se pulverizador costal pressurizado com $\mathrm{CO}_{2}$, acoplado a barra com quatro pontas de pulverização XR 110.02 , à pressão constante de $2 \mathrm{kgf} \mathrm{cm}^{-2}$, aplicando-se volume de calda equivalente a $125 \mathrm{~L} \mathrm{ha}^{-1}$.

Durante o desenvolvimento da cultura, foram realizados tratos fitossanitários, com uma aplicação do inseticida methamidophos $\left(420 \mathrm{~g} \mathrm{ha}^{-1}\right)$ e uma aplicação do fungicida Triciclazole ( $\left.225 \mathrm{~g} \mathrm{ha}^{-1}\right)$, quando a cultura se encontrava com $5 \%$ das panículas emitidas.

Aos 7, 14 e 28 dias após a aplicação (DAA) dos tratamentos herbicidas, foram realizadas as seguintes avaliações: a) fitointoxicação à cultura, por meio de notas visuais, variando de $0 \%$ a $100 \%$, em relação à testemunha, onde zero representou a ausência de injúrias e $100 \%$ a morte das plantas; b) altura de plantas, considerando-se 20 plantas aleatórias por parcela, com trena graduada; c) fitomassa seca da parte aérea de 10 plantas por parcela, as quais foram, posteriormente, secas em estufa de circulação forçada de ar, a $70^{\circ} \mathrm{C}$, por 72 horas, até obtenção de massa constante. Na pré-colheita, foram avaliadas a quantidade de panículas $\mathrm{m}^{-2} \mathrm{e}$ quantidade de grãos panícula $^{-1}$ e, na colheita (115 dias após a semeadura), a produtividade, com padronização para $13 \%$ de umidade nos grãos.

Os dados avaliados foram submetidos a análise de variância e as médias das variáveis significativas comparadas pelo teste Tukey (5\%), utilizando-se o programa estatístico Sisvar. Para a análise de fitointoxicação, os dados foram transformados em arc-seno $(\mathrm{x}+1)^{0.5}$, todavia, os valores apresentados são as médias originais.

\section{RESULTADOS E DISCUSSÃO}

Observou-se efeito fitotóxico à cultura apenas quando da utilização do bispiribaque-sódico, aos 15 e 30 dias após a emergência (DAE) (Tabela 2). Os danos visuais às plantas, quando o herbicida foi aplicado aos $15 \mathrm{DAE}$, foram mais evidentes aos 7 dias após a aplicação (DAA), com $8 \%$ de injúria, caracterizada por leve clorose nas folhas. Todavia, aos 14 DAA, não mais se observou este elevado nível de injúria, apresentando $4 \%$ de fitotoxicidade. Esta recuperação seguiu-se ao longo do ciclo da cultura, quando, aos 28 DAA, não se detectou nenhum sintoma de fitointoxicação à cultura. Aos 30 DAE, observou-se efeito acentuado, com $37 \%$ de danos visuais, caracterizado por intensa clorose e redução de porte das plantas. Este efeito se manteve ao longo do ciclo, demonstrando pouca ou nenhuma capacidade de recuperação da cultura.

O efeito fitotóxico caracterizado pela clorose é típico de herbicidas com ação fisiológica, ou seja, produtos com boa translocação e que interferem diretamente no metabolismo das plantas, como é o caso do bispiribaque-sódico (Rodrigues \& Almeida 2005). A tolerância das plantas aos herbicidas inibidores da ALS está relacionada a uma alteração do gene responsável pela codificação desta enzima (Tranel \& Wright 2002). Uma maior capacidade de metabolização do herbicida pela cultura, associada à diferenciação morfológica das plantas, como es- 
pessura da cutícula (Vidal 2002) e elevado índice de área foliar (Stone \& Pereira 1994), aos 45 DAE, podem explicar a ausência do efeito tóxico às plantas, quando o herbicida bispiribaque-sódico foi aplicado neste período. Estes resultados demonstram que a aplicação de bispiribaque-sódico, até os $30 \mathrm{DAE}$, pode comprometer o desenvolvimento da cultura, principalmente em condições de déficit hídrico, uma vez que a capacidade de metabolização do produto fica prejudicada, em função da redução do metabolismo das plantas. De acordo com Taiz e Zeiger (2004), o metabolismo das plantas é reduzido em condições de déficit hídrico.

A altura das plantas foi significativamente influenciada pelos herbicidas, nas respectivas épocas de aplicação (Tabela 3). A aplicação de penoxsulan, bispiribaque-sódico e pirazossulfurom-etílico, de forma precoce, aos $15 \mathrm{DAE}$, resultou em redução na altura de plantas, na avaliação aos 7 DAA. Todavia, aos 14 DAA, apenas bispiribaque-sódico e 2,4-D causaram redução na altura das plantas. Já aos 28 DAA, não mais se detectou efeito dos herbicidas. Aos 30 DAE, também houve efeito negativo na altura das plantas, sendo as maiores reduções observadas para bispiribaque-sódico, o qual reduziu, em média, $16 \%, 10 \%$ e $11 \%$ a altura das plantas, aos 7,14 e 28 DAA, respectivamente.

Verificou-se que as plantas de arroz de terras altas não recuperam totalmente a altura, quando tratadas com bispiribaque-sódico. Este produto pode oferecer risco para a cultura, principalmente em condições de déficit hídrico, em razão da baixa capacidade metabólica das plantas, nestas condições (Taiz \& Zeiger 2004).

Tabela 2. Fitointoxicação visual em plantas de arroz, após a aplicação de herbicidas, em diferentes épocas, após a emergência da cultura (Nova Xavantina, MT, safra 2009/2010).

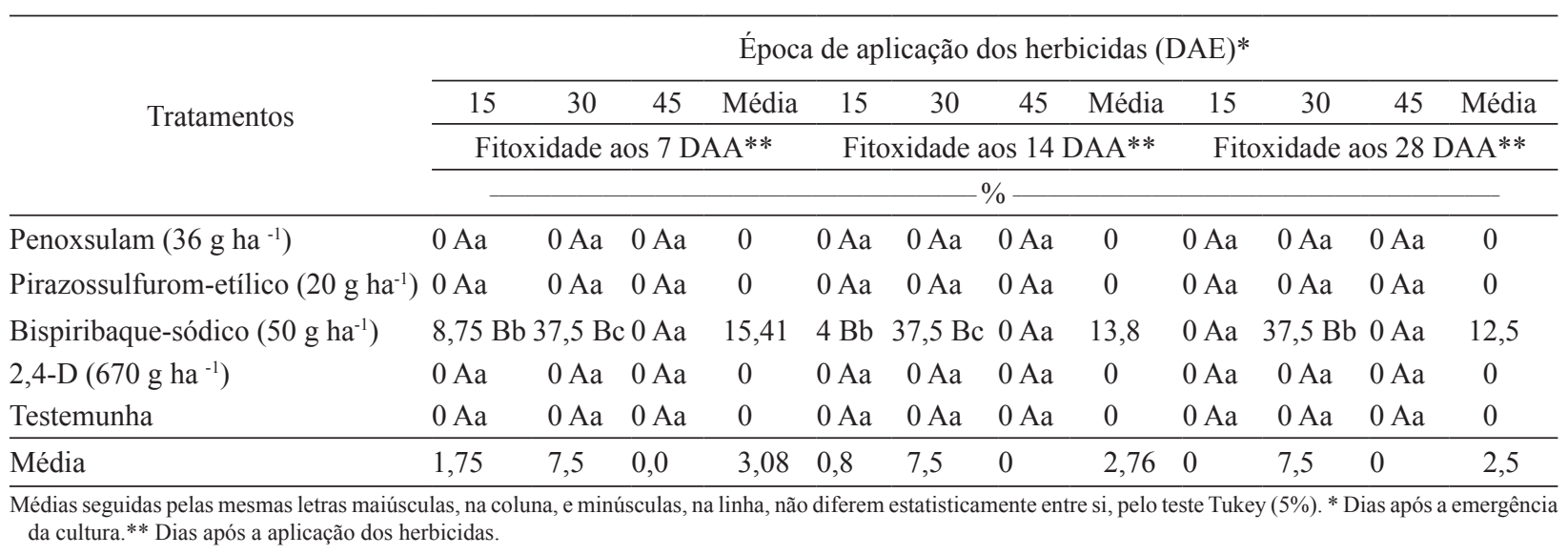

Tabela 3. Altura das plantas de arroz, após a aplicação dos herbicidas, em diferentes épocas, após a emergência da cultura (Nova Xavantina, MT, safra 2009/2010).

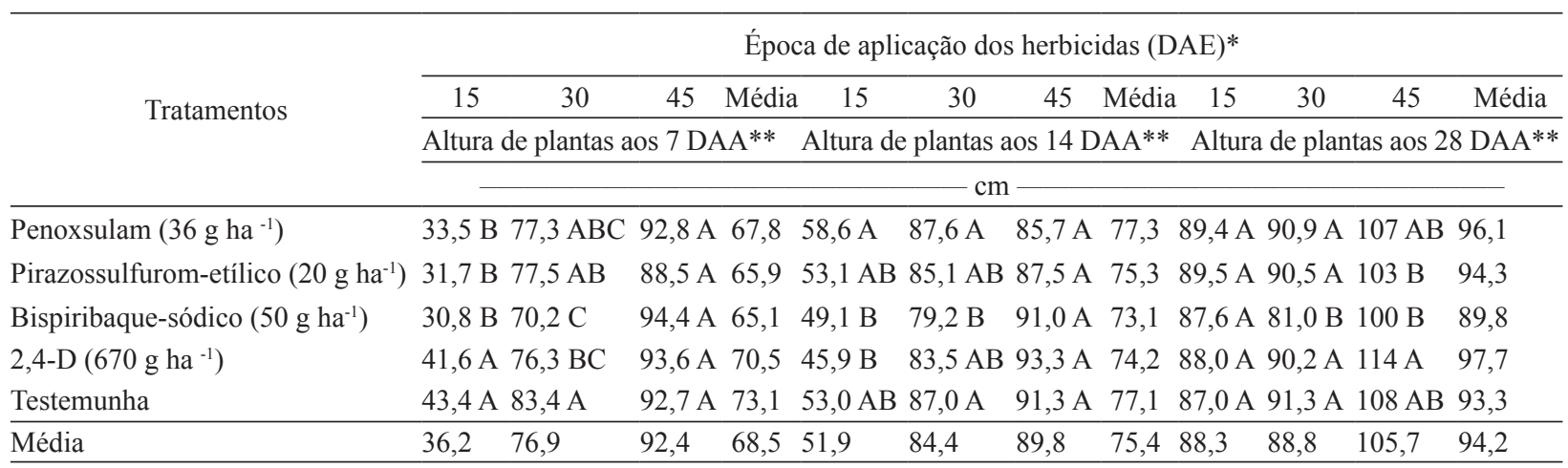

Médias seguidas pelas mesmas letras não diferem estatisticamente entre si, pelo teste Tukey (5\%). * Dias após a emergência da cultura.** Dias após a aplicação dos herbicidas. 
Ressalta-se que a capacidade de metabolização de compostos pelas plantas está diretamente relacionada com sua atividade metabólica. A aplicação tardia (45 DAE) dos herbicidas, na cultura do arroz, não influenciou negativamente a altura das plantas, nas épocas avaliadas. Este resultado já era esperado, pois cultivares de arroz de terras altas de ciclo precoce (105-115 dias), geralmente, aos 45 DAE, já estão cessando o crescimento em altura das plantas. De acordo com Fornasieri Filho \& Fornasieri (2006), cultivares de arroz com ciclo de 155 DAE apresentam fase vegetativa em torno de 50 dias. Com exceção do herbicida bispiribaque-sódico, que causou redução na altura das plantas, mesmo após 28 DAA, quando a aplicação ocorreu aos 30 DAE, de maneira geral, a cultura se recuperou dos efeitos deletérios, o que pode ser atestado pela não significância entre os tratamentos com herbicidas, em relação à testemunha capinada.

$\mathrm{O}$ acúmulo de fitomassa seca da parte aérea foi significativamente influenciado apenas pela aplicação mais tardia (45 DAE) do herbicida 2,4-D, aos 28 DAA (Tabela 4). Todavia, o efeito observado foi positivo, aumentando a fitomassa seca das plantas, em relação à testemunha capinada. Tal fato está associado à maior altura das plantas, observada na aplicação tardia (45 DAE), aos 28 DAA, do herbicida 2,4-D (Tabela 3). De maneira geral, os dados demonstram que as aplicações dos herbicidas penoxsulan, bispiribaque-sódico, pirazossulfurom-etílico e 2,4-D não influenciaram negativamente a fitomassa seca das plantas de arroz. Estes resultados não corroboram os observados por Concenço et al. (2007), em que várias dosagens de bispiribaque-sódico reduziram a altura e fitomassa seca das plantas, em duas cultivares de arroz irrigado. Desta forma, fica evidente o comportamento diferenciado das cultivares de arroz, quando submetidas à aplicação destes herbicidas.

O número de panículas $\mathrm{m}^{-2}$, no arroz, não apresentou significância, quanto à época de aplicação e tipo de herbicida (Tabela 5). No entanto, as médias dos números de panículas $\mathrm{m}^{-2}$ foram maiores na testemunha e menores com a aplicação de 2,4-D, aos 15 DAE, e 2,4-D e penoxsulam, aos 45 DAE. Estes dados assemelham-se aos encontrados por Cobucci \& Portela (2001), que observaram tendência de redução do número de panículas $\mathrm{m}^{-2}$, com 2,4-D amina, aos 10 DAE, na cultura do arroz de terras altas.

$\mathrm{O}$ número de grãos panícula ${ }^{-1}$, no arroz, foi significativamente influenciado, de forma negativa, com 2,4-D, aos 30 DAE, e pirazossulfurom-etílico, aos 45 DAE (Tabela 5), com redução de $26 \%$ e $30 \%$, respectivamente. Cobucci \& Portela (2001) também verificaram redução no número de grãos panícula ${ }^{-1}$, na cultivar Primavera, com a aplicação de 2,4-D, aos 30 DAE. Este efeito foi atribuído ao fato de que, no momento da aplicação, apesar de o número de panículas já estar definido, o número de grãos panícula ${ }^{-1}$ ainda estava por ser definido. Os resultados do presente estudo demonstram que o número de grãos panícula ${ }^{-1}$ foi influenciado pelas épocas de aplicação apenas com 2,4-D, sendo a melhor época de aplicação aos 15 DAE.

Houve efeito significativo na produtividade de grãos de arroz, com a aplicação dos herbicidas, nas diferentes épocas, havendo interação entre estes fatores (Tabela 5). As maiores produtividades foram obtidas

Tabela 4. Fitomassa seca das plantas de arroz, após a aplicação dos herbicidas, em diferentes épocas, após a emergência da cultura (Nova Xavantina, MT, safra 2009/2010).

\begin{tabular}{|c|c|c|c|c|c|c|c|c|c|c|c|}
\hline \multirow{4}{*}{ Tratamentos } & \multicolumn{11}{|c|}{ Época de aplicação dos herbicidas (DAE)* } \\
\hline & 15 & 30 & 45 & Média & 15 & 30 & 45 & Média & 15 & 45 & Média \\
\hline & \multicolumn{4}{|c|}{ Fitomassa seca aos $7 \mathrm{DAA}^{* *}$} & \multicolumn{4}{|c|}{ Fitomassa seca aos $14 \mathrm{DAA}^{* *}$} & \multicolumn{3}{|c|}{ Fitomassa seca aos $28 \mathrm{DAA}^{* *}$} \\
\hline & \multicolumn{10}{|c|}{ - g $10^{-1}$ plantas } & + \\
\hline Penoxsulam (36 $\left.\mathrm{g} \mathrm{ha}^{-1}\right)$ & 2,3 & 7,7 & 17,7 & $9,2^{\text {ns }}$ & $4,5 \mathrm{~A}$ & $13,7 \mathrm{~A}$ & $22,7 \mathrm{AB}$ & 13,6 & $14,2 \mathrm{~A}$ & 22,0 A $26,2 \mathrm{BC}$ & 20,8 \\
\hline Pirazossulfurom-etílico (20 $\left.\mathrm{g} \mathrm{ha}^{-1}\right)$ & 2,1 & 8,6 & 17,7 & 9,5 & $4,5 \mathrm{~A}$ & $14,7 \mathrm{~A}$ & $19,7 \mathrm{AB}$ & 13,0 & $13,2 \mathrm{~A}$ & 19,0 A 29,7 B & 20,6 \\
\hline Bispiribaque-sódico (50 $\left.\mathrm{g} \mathrm{ha}^{-1}\right)$ & 2,0 & 7,2 & 19,2 & 9,5 & $4,4 \mathrm{~A}$ & $13,2 \mathrm{~A}$ & $21,7 \mathrm{AB}$ & 13,1 & $14,5 \mathrm{~A}$ & $18,0 \mathrm{~A} \quad 31,5 \mathrm{AB}$ & 21,3 \\
\hline $2,4-\mathrm{D}\left(670 \mathrm{~g} \mathrm{ha}^{-1}\right)$ & 2,5 & 9,1 & 16,7 & 9,4 & $4,0 \mathrm{~A}$ & $14,5 \mathrm{~A}$ & $21,7 \mathrm{AB}$ & 13,4 & $13,7 \mathrm{~A}$ & 23,5 A 39,2 A & 25,5 \\
\hline Testemunha & 2,6 & 9,7 & 17,7 & 10,0 & $4,8 \mathrm{~A}$ & $13,5 \mathrm{~A}$ & $24,5 \mathrm{~A}$ & 14,2 & $14,5 \mathrm{~A}$ & 24,5 A 25,7 BC & 21,5 \\
\hline Média & 2,3 & 8,4 & 17,8 & 9,5 & 4,5 & 13,9 & 22,1 & 13,5 & 14,0 & $21,4 \quad 30,5$ & 21,9 \\
\hline
\end{tabular}


Tabela 5. Número de panículas, número de grãos por panícula e produtividade de arroz, após a aplicação dos herbicidas, em diferentes épocas, após a emergência da cultura (Nova Xavantina, MT, safra 2009/2010).

\begin{tabular}{|c|c|c|c|c|c|c|c|c|c|c|c|}
\hline \multirow{4}{*}{ Tratamentos } & \multicolumn{11}{|c|}{ Época de aplicação dos herbicidas (DAE)* } \\
\hline & 15 & 30 & 45 & Média & 15 & 30 & 45 & Média & 15 & 30 & Média \\
\hline & \multirow{2}{*}{\multicolumn{4}{|c|}{$\mathrm{N}^{\circ}$ panículas $\mathrm{m}^{-2}$}} & \multirow{2}{*}{\multicolumn{4}{|c|}{$\mathrm{N}^{\mathrm{o}}$ grãos panícula ${ }^{-2}$}} & \multicolumn{3}{|c|}{ Produtividade } \\
\hline & & & & & & & & & 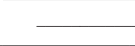 & $\mathrm{kg} \mathrm{ha}^{-1}$ & - \\
\hline Penoxsulam (36 $\left.\mathrm{g} \mathrm{ha}^{-1}\right)$ & 166 & 194 & 113 & $158^{\mathrm{ns}}$ & $117 \mathrm{Aa}$ & $121 \mathrm{ABa}$ & $135 \mathrm{ABa}$ & 124 & $1.909 \mathrm{Ab}$ & $2.686 \mathrm{Aa} \quad 804 \mathrm{Bc}$ & 1.800 \\
\hline Pirazossulfurom-etílico (20 $\left.\mathrm{g} \mathrm{ha}^{-1}\right)$ & 180 & 168 & 167 & 172 & $123 \mathrm{Aa}$ & $128 \mathrm{ABa}$ & $107 \mathrm{Ba}$ & 119 & $2.441 \mathrm{Aa}$ & $2.543 \mathrm{Aa} 1.228 \mathrm{BCb}$ & 2.071 \\
\hline Bispiribaque-sódico $\left(50 \mathrm{~g} \mathrm{ha}^{-1}\right)$ & 206 & 170 & 178 & 185 & $123 \mathrm{Aa}$ & $135 \mathrm{ABa}$ & $148 \mathrm{Aa}$ & 135 & $1.833 \mathrm{Ab}$ & $2.798 \mathrm{Aa} 1.585 \mathrm{ABCb}$ & 2.072 \\
\hline $2,4-\mathrm{D}\left(670 \mathrm{~g} \mathrm{ha}^{-1}\right)$ & 147 & 179 & 137 & 154 & $147 \mathrm{Aa}$ & $111 \mathrm{Bb}$ & $137 \mathrm{ABab}$ & 132 & $2.515 \mathrm{Aa}$ & $2.613 \mathrm{Aa} 2.102 \mathrm{ABa}$ & 2.410 \\
\hline Testemunha & 195 & 197 & 193 & 195 & $153 \mathrm{Aa}$ & $155 \mathrm{Aa}$ & $151 \mathrm{Aa}$ & 153 & $2.213 \mathrm{Aa}$ & $2.460 \mathrm{Aa} 2.250 \mathrm{Aa}$ & 2.307 \\
\hline Média & 158 & 179 & 181 & 173 & 133 & 130 & 136 & 133 & $1.909 \mathrm{Ab}$ & $2.686 \mathrm{Aa} \quad 804 \mathrm{Bc}$ & 1.800 \\
\hline
\end{tabular}

com a aplicação dos herbicidas aos $30 \mathrm{DAE}$. De acordo com Stone \& Moreira (2000) e Oliveira et al. (2002), variáveis como número de panículas e peso de grãos podem não se correlacionar com a produtividade, em razão da desuniformidade no estande, luz e espaço físico, o que dificulta sua medição e, consequentemente, proporciona altos coeficientes de variação.

Ao se analisarem os efeitos dos herbicidas sobre a produtividade de grãos, em cada época de aplicação, verificou-se que os herbicidas influenciaram na produtividade apenas quando aplicados aos $45 \mathrm{DAE}$, com destaque para os herbicidas penoxsulan e pirazossulfurom-etílico, que proporcionaram as menores produtividades, em relação à testemunha capinada (Tabela 5).

De maneira geral, as maiores produtividades foram obtidas com a aplicação dos herbicidas aos 30 DAE, demonstrando ser esta a melhor época para sua aplicação na cultura do arroz cv. Cambará. Estes dados corroboram os obtidos por Cobucci \& Portela (2001), que observaram que a época mais adequada para a aplicação dos herbicidas em pós-emergência, em diferentes cultivares de arroz, foi aos 30 DAE. Estes mesmos autores destacam o fato de que, em função de $o$ arroz encontrar-se em intenso perfilhamento, antes dos 30 DAE, a aplicação de determinados herbicidas pode reduzir sensivelmente o número de panículas.

O efeito prejudicial do penoxsulan e pirazossulfurom-etílico à produtividade é um reflexo do menor número de panículas (não-significativo) e grãos por panícula, respectivamente. Por se tratarem de moléculas capazes de inibir a enzima ALS, envolvida na biossíntese de aminoácidos que são precursores de síntese protéica e crescimento de estruturas meristemáticas (reprodutivas), estas podem afetar o desenvolvimento das panículas, número de espiguetas por panícula e o número de grãos por panícula. Ray (1984) e Claus (1987) constataram que os inibidores de ALS, ao serem absorvidos, são translocados para regiões meristemáticas, inibindo a divisão celular e causando redução do crescimento e morte de tecidos.

A baixa produtividade média observada no experimento (Tabela 5) se deu em função da ocorrência de períodos de estiagem, durante a safra (Figura 1), coincidindo com o estádio reprodutivo da cultura. A deficiência hídrica é a principal responsável pela baixa produtividade e instabilidade do arroz de terras altas (Steinmetz et al. 2006).

\section{CONCLUSÕES}

1. O herbicida bispiribaque-sódico $\left(50 \mathrm{~g} \mathrm{ha}^{-1}\right)$ causa fitointoxicação à cultivar Cambará, semeada em sistema de arroz de terras altas, quando aplicado aos 15 e 30 dias após a emergência da cultura.

2. Os herbicidas testados não influenciaram negativamente a fitomassa seca da parte aérea das plantas de arroz, em semeadura no sistema de terras altas.

3. A aplicação de penoxsulan $\left(36 \mathrm{~g} \mathrm{ha}^{-1}\right)$ e pirazossulfurom-etílico (20 $\left.\mathrm{g} \mathrm{ha}^{-1}\right)$, aos 45 dias após a emergência da cultura, reduz significativamente a produtividade da cultivar Cambará, semeada em sistema de arroz de terras altas.

4. Os herbicidas penoxsulan, bispiribaque-sódico e pirazossulfurom-etílico são boas alternativas no manejo de plantas daninhas, na cultura do arroz cv. Cambará de terras altas, sendo 30 dias após a emergência a melhor época para aplicação destes produtos. 


\section{REFERÊNCIAS}

BELING, R. R. Anuário brasileiro do arroz 2007. Santa Cruz do Sul: Gazeta, 2007.

CLAUS, J. S. Chlorimuron-ethyl (classic): a new broadleaf postemergence herbicide in soybean. Weed Technology, Champaign, v. 1, n. 1, p. 114-115, 1987.

COBUCCI, T.; NOLDIN, J. A. Plantas daninhas e seu controle. In: VIEIRA, N. R. A.; SANTOS, A. B.; SANT'ANA, E. P. (Eds.). Cultura do arroz no Brasil. Santo Antônio de Goiás: Embrapa, 1999. p. 375-415.

COBUCCI, T.; PORTELA, C. Seletividade de herbicidas aplicados em diferentes estádios de desenvolvimento na cultura do arroz de terras altas. Planta Daninha, Viçosa, v. 19, n. 3, p. 359-366, 2001.

CONCENÇO, G. et al. Sensibilidade de plantas de arroz ao herbicida byspiribac-sodium em função de doses e locais de aplicação. Planta daninha, Viçosa, v. 25, n. 3 , p. 629-637, 2007.

EMPRESA BRASILEIRA DE PESQUISA AGROPECUÁRIA (Embrapa). Centro Nacional de Pesquisa de Solos. Sistema brasileiro de classificação de solos. Rio de Janeiro: Embrapa, 1999.

FERREIRA, C. M.; VILLAR, P. M. D. Cultivo do arroz de terras altas no Brasil. Santo Antônio de Goiás: Embrapa Arroz e Feijão, 2003.

FORNASIERI FILHO, D.; FORNASIERI, J. L. Manual da cultura do arroz. Jaboticabal: Funep, 2006.

KLUTHCOUSKI, J.; PINHEIRO, B. S.; YOKOYAMA, L. P. O arroz nos sistemas de cultivo do Cerrado. In: CONFERENNCIA INTERNACIONAL DE ARROZ PARA A AMÉRICA LATINA E O CARIBE, 9., 1994, Goiânia. Anais... Goiânia: Embrapa-CNPAF, 1995. p. 95-115.

LEITE, C. R. F.; ALMEIDA, J. C. V.; PRETE, C. E. C. Aspectos fisiológicos, bioquímicos e agronômicos dos herbicidas inibidores da ALS (AHAS). Londrina: Ed. dos Autores, 1998.

OLIVEIRA, T. K.; CARVALHO, G. J.; MORAES, R. N. S. Plantas de cobertura e seus efeitos sobre o feijoeiro em plantio direto. Pesquisa Agropecuária Brasileira, Brasília, DF, v. 37, n. 8, p. 1079-1087, 2002.
PACHECO, L. P. et al. Sobressemeadura da soja como técnica para supressão da emergência de plantas daninhas. Planta Daninha, Viçosa, v. 27, n. 3, p. 455-463, 2009.

PINHEIRO, B. S. Características morfológicas da planta relacionadas à produtividade. In: SANTOS, A. B.; STONE, L. F.; VIEIRA, N. R. A. (Eds.). A cultura do arroz no Brasil. 2. ed. Santo Antonio de Goiás: Embrapa Arroz e Feijão, 2006. p. 209-256.

RAHMAN, M. A. Critical period of weed competition in transplanted aman rice. Bangladesh Journal of Scientific and Industrial Research, Bangladesh, v. 27, n. 1-2, p. 151156, 1992.

RAY, T. B. Site of action of chlorsulfuron. Plant Physiology, Melbourne, v. 75, n. 3, p. 827-831, 1984.

RODRIGUES, B. N; ALMEIDA, F. S. Guia de herbicidas. 5. ed. Londrina: Ed. dos Autores, 2005.

STEINMETZ, S.; SILVA, S. C.; SANTANA, N. M. P. Clima. In: SANTOS, A. B.; STONE, L. F.; VIEIRA, N. R. A. (Eds.). A cultura do arroz no Brasil. Santo Antônio de Goiás: Embrapa Arroz e Feijão, 2006. p. 117-160.

STONE, L. F.; PEREIRA, A. L. Sucessão arrozfeijão irrigados por aspersão: efeitos do espaçamento entre linhas, adubação e cultivar no crescimento, desenvolvimento radicular e consumo de água do arroz. Pesquisa Agropecuária Brasileira, Brasília, DF, v. 29, n. 10, p. 1557-1592, 1994.

STONE, L. F.; MOREIRA, J. A. A. Efeitos de sistemas de preparo de solo no uso da água e na produtividade do feijoeiro. Pesquisa Agropecuária Brasileira, Brasília, DF, v. 35, n. 4, p. 835-841, 2000.

TAIZ, L.; ZEIGER, E. Fiosiologia vegetal. 3. ed. Porto Alegre: Artmed, 2004.

TRANEL, P. J.; WRIGHT, T. R. Resistence of weeds to ALS-inhibiting herbicides: what have we learned? Weed Science, Champaign, v. 50, n. 6, p. 700-712, 2002.

VIDAL, R. Ação dos herbicidas. Porto Alegre: Evangraf, 2002. 